\title{
Adverse social determinants and risk for congenital anomalies
}

\author{
Mariela S. Pawluk, M.D. ${ }^{a, d}$, Hebe Campaña, M.D. ${ }^{a, d, e}, J u a n$ A. Gili, B.S. ${ }^{a, c}$, \\ Belén Comas, B.S. ${ }^{a, c}$, Lucas G. Giménez, B.S. ${ }^{a, c}$, María J. Villalba, B.S., ${ }^{a, d}$ \\ Sandra C. Scala, B.S. ${ }^{a, d}$, Fernando A. Poletta, M.D..$^{a, b, c}$ and \\ Jorge S. López Camelo, M.D., , $, b, c, d^{-}$
}

\begin{abstract}
Introduction.Differentstudieshaverelated familiar and regional adverse social conditions to perinatal outcome (neonatal mortality, low birth weight and prematurity); however,fewstudieshavestudied the effect of poverty on congenital anomalies.

Objective.To assess the hazard ratio of 25 congenital anomalies and adverse social determinants as per the socioeconomic level of families and regions.

Population and methods.Exploratory, casecontrol study using data from the Latin-American Collaborative Study of Congenital Malformations (EstudioColaborativoLatinoamericanodeMalformaciones Congénitas, ECLAMC). The sample consisted of 3786 livenewborninfantswithasinglemalformation and 13344 controls selected among 546129 births occurred in 39 hospitals from Argentina in the 19922001 period. Both direct and indirect (residence) risks (OR) were estimated, together with the interaction between the individual and residential socioeconomic levels for each of the 25 congenital anomalies.
\end{abstract}

a. Latin-American Collaborative Study of Congenital Malformations (ECLAMC) at Clinical Research and Medical Education Center, CONICET.

b. National Institute of Medical Population Genetics (INAGEMP), Brazil

c. Clinical Research and Medical Education Center (CEMIC).

d. Multidisciplinary Institute of Cell Biology (IMBICE), CICPBA-CONICET.

e. Scientific Research Commission of Buenos Aires Province (CICPBA).

E-mail Address:

Jorge S. López Camelo,

M.D.: jslc@eclamc.org

Conflict of interest:

None.

Received: 9-10-2013

Accepted: 1-2-2014 multidimensional concept and is usually measured using observable variables combined into a single index. In general, poverty indices measure the proportion of families within a defined geographical unit with a combination of circumstances indicating fewer resources or a great need of basic services, or both. ${ }^{2}$

Different studies have studied familiar and regional adverse social determinants in relation to perinatal outcome, such as neonatal mortality, ${ }^{3}$ low birth weight ${ }^{4}$ and prematurity, ${ }^{5}$ but not in relation to congenital anomalies. Among the few reported causes on this issue, a low maternal socioeconomic level (SEL) has been associated with a higher risk of having a newborn infant with cleft lip, ${ }^{6,9}$ neural tube defects, ${ }^{7}$ and heart diseases. ${ }^{8,9}$

The etiology of poverty in relation to congenital anomalies is varied, indirect and non-specific, and includes environmental conditions (pollution, violence, stress, etc.), lack of antenatal care, adverse reproductive behavior, ${ }^{10}$ difficulties to access health services during pregnancy, ${ }^{11}$ lack of information on prevention during pregnancy, and exposure to tobacco and alcohol as part of their lifestyle. ${ }^{12}$

Our hypothesis was that adverse social conditions directly or indirectly might increase the hazard ratio of some specific congenital anomalies.

The aim of the present study is to evaluate the hazard ratio of 25 congenital anomalies and adverse social determinants as per the socioeconomic level of families and regions. 


\section{MATERIAL AND METHODS}

This is an exploratory, case-control study, matched by time and place of birth using the data obtained from the Latin-American Collaborative Study of Congenital Malformations (EstudioColaborativoLatinoamericano de MalformacionesCongénitas, ECLAMC). ${ }^{13}$

Twenty-five congenital anomalies were studied. These had been selected because of their clinical and biological relevance and/or because of their impact on neonatal morbidity and mortality (Table 1), that were diagnosed before hospital discharge.

\section{Development of the family socioeconomic level index}

The family socioeconomic level (f-SEL) index was created using the factor analysis methodology based on different outcome measures directly or indirectly related to the socioeconomic level. The included outcome measures were maternal age, multigravidity, maternal and paternal education level, maternal and paternal employment modality, and health insurance system (no insurance or some insurance). All possible combinations among the studied outcome measures were evaluated, and the most

TABLE 1. Number of cases and controls distributed by family socioeconomic level ( $f$-SEL) as per the regional SEL ( $r$-SEL) index

\begin{tabular}{|c|c|c|c|c|c|c|c|c|c|c|c|}
\hline \multirow[b]{2}{*}{ f-SEL } & \multicolumn{5}{|c|}{ Middle and low r-SEL (UBNs $<18 \%$ ) } & \multicolumn{5}{|c|}{ High r-SEL (UBNs $\geq 18 \%$ ) } & \multirow[b]{2}{*}{ Total } \\
\hline & Q1-low & Q2 & Q3 & Q4 & Q5-high & Q1-low & Q2 & Q3 & Q4 & Q5-high & \\
\hline Anomaly & $\mathrm{N}$ & $\mathrm{N}$ & $\mathrm{N}$ & $\mathrm{N}$ & $\mathrm{N}$ & $\mathrm{N}$ & $\mathrm{N}$ & $\mathrm{N}$ & $\mathrm{N}$ & $\mathrm{N}$ & $\mathrm{N}$ \\
\hline Omphalocele & 7 & 3 & 6 & 7 & 7 & 4 & 2 & 2 & 4 & 2 & 44 \\
\hline Gastroschisis & 6 & 9 & 11 & 21 & 27 & 6 & 3 & 6 & 6 & 2 & 97 \\
\hline Anencephaly & 28 & 29 & 32 & 54 & 54 & 35 & 17 & 24 & 33 & 16 & 322 \\
\hline Spina bifida & 33 & 31 & 29 & 52 & 72 & 24 & 16 & 7 & 26 & 18 & 308 \\
\hline Hydrocephalus & 42 & 26 & 25 & 52 & 63 & 25 & 8 & 10 & 18 & 12 & 281 \\
\hline Cephalocele & 11 & 5 & 7 & 11 & 13 & 8 & 10 & 0 & 10 & 5 & 80 \\
\hline Microtia & 20 & 8 & 10 & 29 & 35 & 11 & 8 & 9 & 15 & 12 & 157 \\
\hline Cleft lip & 60 & 31 & 54 & 76 & 83 & 62 & 41 & 39 & 46 & 27 & 519 \\
\hline Cleft palate & 8 & 6 & 9 & 13 & 22 & 4 & 5 & 13 & 12 & 7 & 99 \\
\hline Esophageal atresia & 6 & 5 & 6 & 14 & 17 & 3 & 3 & 6 & 4 & 2 & 66 \\
\hline Imperforate anus & 12 & 3 & 5 & 20 & 26 & 9 & 8 & 8 & 10 & 5 & 106 \\
\hline Truncus arteriosus & 15 & 26 & 17 & 26 & 39 & 5 & 7 & 5 & 16 & 9 & 165 \\
\hline ASD & 5 & 4 & 3 & 6 & 12 & 4 & 1 & 1 & 6 & 4 & 46 \\
\hline VSD & 41 & 28 & 35 & 49 & 69 & 29 & 18 & 23 & 23 & 12 & 327 \\
\hline Hypospadias & 19 & 14 & 8 & 22 & 62 & 10 & 7 & 9 & 5 & 3 & 159 \\
\hline Postaxial polydactyly & 73 & 37 & 37 & 80 & 108 & 26 & 20 & 34 & 30 & 21 & 466 \\
\hline Preaxial polydactyly & 23 & 13 & 6 & 21 & 23 & 12 & 9 & 8 & 8 & 5 & 128 \\
\hline $\begin{array}{l}\text { Terminal transverse } \\
\text { limb reduction }\end{array}$ & 7 & 7 & 3 & 6 & 17 & 5 & 5 & 3 & 3 & 1 & 57 \\
\hline Preaxial limb reduction & 2 & 2 & 1 & 2 & 2 & 4 & 1 & 1 & 2 & 1 & 18 \\
\hline Diaphragmatic hernia & 17 & 6 & 12 & 14 & 14 & 12 & 6 & 6 & 6 & 6 & 99 \\
\hline Pectoralis major agenesis & 1 & 0 & 0 & 2 & 3 & 5 & 5 & 3 & 3 & 1 & 23 \\
\hline Ambiguous genitalia & 1 & 0 & 3 & 2 & 6 & 1 & 0 & 1 & 3 & 1 & 18 \\
\hline Renal agenesis & 2 & 2 & 0 & 4 & 8 & 0 & 1 & 0 & 0 & 0 & 17 \\
\hline Renal polycystosis & 10 & 7 & 11 & 18 & 23 & 3 & 2 & 3 & 1 & 5 & 83 \\
\hline Hydronephrosis & 9 & 7 & 8 & 17 & 42 & 2 & 1 & 2 & 5 & 8 & 101 \\
\hline Total anomalies & 458 & 309 & 338 & 618 & 847 & 309 & 204 & 223 & 295 & 185 & 3786 \\
\hline Controls & 1532 & 1109 & 1210 & 2201 & 2929 & 878 & 808 & 792 & 1228 & 657 & 13344 \\
\hline
\end{tabular}

ASD: atrial septal defect. VSD: ventricular septal defect. 
consistent and reliable combination was selected using Cronbach's alpha coefficient. The best combination was the one that included maternal and paternal education level and paternal employment modality, with a Cronbach's alpha of 0.80. Maternal and paternal education levels were grouped into eight categories: 1 . does not read, 2. able to read and write, 3. incomplete primary school, 4 . complete primary school, 5 . incomplete secondary school, 6 . complete secondary school, 7. incomplete university, and 8. complete university. Paternal employment modality was defined using eight categories: 1 . household chores, 2. unemployed, 3. unskilled worker, 4 . skilled worker, 5 . autonomous worker, 6. employee, 7. employer, 8. professional. The three outcome measures for each newborn infant family were added and the resulting score ranged between 3 and 24. Given that such score did not have a normal distribution, it was divided into quintiles, thus generating the definitive f-SEL, where the first quintile (Q1) corresponded to the lowest SEL and the fifth quintile (Q5) accounted for the highest SEL (Table 1).

\section{Regional socioeconomic level index}

Geographic regions were identified and a regional socioeconomic level (r-SEL) index was allocated to each region using census data from the unmet basic need (UBN) index obtained during the 2001 National Population, Households and Housing Census conducted by the National Statistics and Censuses Institute (Instituto Nacional de Estadísticas y Censos de la Argentina, INDEC).

An UBN value was assigned to each of the 25 Argentine municipalities/districts where the 39 maternity centers in the ECLAMC network are located.

In order to identify geographic regions with UBNs significantly higher than those observed for the total sample, an analysis was conducted using the StatScan software and the method developed by M. Kulldorff and N. Nagarwalla. ${ }^{14}$

\section{Adverse social determinants}

The following outcome measures were selected as possible independent risk factors and/or confounding factors associated with the poverty index and the congenital anomaly: paternal age, parental sibship, maternal and paternal native descent (defined as those cases that have a Latin American descent, as far as the family memory recalls, including American Indian and creole origin), maternal age, number of pregnancies, impaired fecundity (fertility treatments: YES/NO), number of months with parents living together before the mother got pregnant, a different father compared to the previous pregnancy, exposure to acute or chronic conditions during the first trimester of gestation, use of medications, and number of antenatal care visits during pregnancy.

Confounding factors were controlled using a statistical technique called propensity scores. ${ }^{15}$ For this, the combination of outcome measures defined above was analyzed, obtaining the most adequate propensity score. Risk analysis for the 14 congenital anomalies due to exposure to a low socioeconomic level were adjusted stratifying the sample by the obtained propensity scores.

An ordinal regression was used to assess the outcome measures associated with the f-SEL: eachf-SEL quintile was considered a dependent outcome measure, and the adverse social determinants defined above were considered independent outcome measures.

The f-SEL dose/response effect on the congenital anomaly was assessed using the Woolf's test, ${ }^{16}$ which analyzes the odds ratio(OR) trend with a chi-square with one degree of freedom.

The risk for a low f-SEL considering the level of development of the region was assessed using a multilevel logistic regression, ${ }^{17}$ which recognizes data hierarchical organization. Associations were estimated calculating the OR and the corresponding $95 \%$ confidence intervals. The interactions between the f-SEL and the r-SEL were evaluated by grouping individuals into four categories: 1. mothers with low f-SEL (quintiles 1 and 2) who live in high r-SEL regions $\left(\mathrm{OR}_{11}\right)$, 2. mothers with a low f-SEL (quintiles 1 and 2) who live in low r-SEL regions (low f-SEL effect, $\left.\mathrm{OR}_{12}\right), 3$. mothers with a non-low f-SEL (quintiles 3, 4 and 5) who live in high r-SEL regions (residence region effect, $\mathrm{OR}_{21}$ ), and 4. mothers with a non-low f-SEL (quintiles 3,4 and 5) who live in low r-SEL regions (reference group, $\mathrm{OR}_{22}$ ). Direct and indirect effects of a low $\mathrm{f}$-SEL on the congenital anomaly were estimated. ${ }^{18}$ Synergy was measured using Rothman's index (S). ${ }^{19}$ Synergy is considered to be present when the risk of a mother with a low SEL who lives in a deprived region is higher than the individual sum of both risks:

$$
\mathrm{S}=\frac{\mathrm{OR}_{11}-1}{\mathrm{OR}_{12}+\mathrm{OR}_{21}}
$$


Anomalies selected were those with an occurrence of at least 100 cases. The sample size was estimated for a risk factor with an exposure of at least $20 \%$ and that would allow to detect a minimum risk at least two times higher, with an $80 \%$ power (beta) and an alpha significance level of $5 \%$.

\section{RESULTS}

The sample consisted of 3786 live newborn infants with a single congenital anomaly and 13344 live newborn infants with no congenital anomalies (controls) selected out of a total of 546129 births occurred in 39 hospitals from Argentina (Annex I) examined in the 19922001 period.

Four regions were identified; three had high levels of UBNs (between 19\% and 21\%) and corresponded to the following districts: 1) Bariloche and Futaleufú (south of Argentina); 2) Esteban Echeverría, Lomas de Zamora and Almirante Brown (Province of Buenos Aires); 3) Dr. Manuel Belgrano, San Miguel de Tucumán and La Rioja (northwest region of Argentina), and other region with a low level of UBNs $(7.8 \%)$, the Autonomous City of Buenos Aires. The remaining
16 districts had a middle level of UBNs (13\%). The definitive r-SEL was established by grouping the 25 municipalities/districts into the three resulting categories: 1. high r-SEL (districts with UBNs between $19 \%$ and $21 \%$ ), 2. middle r-SEL $(\mathrm{UBNs}=13 \%)$ and 3 . low $\mathrm{r}-\mathrm{SEL}(\mathrm{UBNs}=7.8 \%)$. Table 1 shows the number of cases for each congenital anomaly by family socioeconomic level (quintiles) for two geographic regions according to the level of development: high and middle r-SEL and low r-SEL.

The f-SEL index showed that low socioeconomic levels were significantly associated with a higher frequency of parental sibship, native descent, maternal age younger than 19 years old, more than four pregnancies, low number of antenatal care visits, and residence in deprived regions (Table 2).

In relation to maternal conditions during the first trimester of gestation, a higher rate of scabies, AIDS, syphilis, use of quinine and abortion medications (Hipofisina, Cristerona, unspecified hormones) were observed in lower SELs.

The propensity score that showed the most adequate matching degree between cases and controls included maternal age, gravidity order,

TABLE 2. Social adverse determinants by family socioeconomic level (f-SEL) in controls (percentage)

\begin{tabular}{|c|c|c|c|c|c|c|c|c|}
\hline \multirow{2}{*}{$\frac{\text { Quintiles f-SEL }}{\mathrm{N}}$} & & \multirow{2}{*}{$\frac{\text { Low Q1 }}{2410}$} & \multirow{2}{*}{$\frac{\text { Q2 }}{1917}$} & \multirow{2}{*}{$\frac{\text { Q3 }}{2002}$} & \multirow{2}{*}{$\frac{\text { Q4 }}{3429}$} & \multirow{2}{*}{$\begin{array}{c}\text { High Q5 } \\
3586\end{array}$} & \multicolumn{2}{|c|}{ Trend } \\
\hline & & & & & & & $\mathrm{b}$ & $\mathrm{p}$ \\
\hline \multirow[t]{2}{*}{ Median } & & 9 & 11 & 12 & 13 & 16 & & \\
\hline & & $\%$ & $\%$ & $\%$ & $\%$ & $\%$ & & \\
\hline \multirow[t]{3}{*}{ f-SEL index } & Low maternal education level & 67 & 19 & 11 & 5 & 1 & -3.16 & - \\
\hline & Low paternal education level & 66 & 16 & 9 & 4 & 1 & -3.00 & - \\
\hline & Low paternal employment modality & 90 & 77 & 42 & 20 & 4 & -3.61 & - \\
\hline \multirow{3}{*}{$\begin{array}{l}\text { Demographic } \\
\text { characteristic }\end{array}$} & Paternal age $\leq 19$ years old & 7 & 9 & 10 & 7 & 4 & -0.19 & 0.297 \\
\hline & Paternal age $\geq 39$ years old & 16 & 10 & 11 & 10 & 10 & -0.02 & 0.839 \\
\hline & Sibship & 0.4 & 0.4 & 0.25 & 0.4 & 0.2 & -1.30 & 0.002 \\
\hline Ethnic descent & Native & 95 & 95 & 94 & 90 & 71 & -1.20 & $<0.001$ \\
\hline \multirow{7}{*}{$\begin{array}{l}\text { Reproductive } \\
\text { behavior }\end{array}$} & Maternal age $\leq 19$ years old & 23 & 25 & 24 & 21 & 13 & -0.52 & $<0.001$ \\
\hline & Maternal age $\geq 35$ years old & 15 & 10 & 11 & 9 & 11 & 0.09 & 0.241 \\
\hline & Primigravidity & 19 & 26 & 27 & 29 & 37 & 0.00 & - \\
\hline & Multigravidity $\geq 4$ & 49 & 36 & 36 & 30 & 21 & -0.38 & $<0.001$ \\
\hline & Impaired fecundity & 6 & 8 & 10 & 12 & 10 & 0.05 & 0.545 \\
\hline & Period living together $<1$ year & 4 & 2 & 4 & 3 & 3 & 0.24 & 0.070 \\
\hline & Different father & 14 & 13 & 13 & 13 & 13 & -0.10 & 0.185 \\
\hline Antenatal care & Antenatal care $\leq 5$ & 47 & 41 & 36 & 31 & 22 & -0.24 & $<0.001$ \\
\hline \multirow{3}{*}{$\begin{array}{l}\text { Exposure during } \\
\text { the first trimester }\end{array}$} & Acute conditions & 23 & 25 & 29 & 29 & 31 & -0.05 & 0.358 \\
\hline & Chronic conditions & 11 & 11 & 13 & 13 & 14 & -0.09 & 0.202 \\
\hline & Use of medications & 37 & 40 & 45 & 47 & 54 & 0.21 & $<0.001$ \\
\hline \multirow{3}{*}{$\begin{array}{l}\text { Regional } \\
\text { development level } \\
\text { (r-SEL) }\end{array}$} & Low & 36 & 42 & 40 & 36 & 18 & -0.31 & $<0.001$ \\
\hline & Middle & 58 & 48 & 45 & 46 & 51 & - & - \\
\hline & High & 5 & 10 & 15 & 18 & 31 & 0.40 & $<0.00$ \\
\hline
\end{tabular}


number of antenatal care visits, and native descent.

Significant differences were observed between cases and controls for a low f-SEL (Q1), maternal age $\geq 35$, gravidity order $\geq 4$, low number of antenatal care visits $(\leq 5)$, higher rate of acute conditions during the first trimester of gestation, chronic conditions, and use of medications during the first trimester of gestation (Table 3).

Cleft lip with/without cleft palate and ventricular septal defect showed a dose/response effect in relation to the f-SEL. For both defects, the risk of having an anomaly was statistically significant in a lower SEL. When both direct and indirect f-SEL effects were analyzed, both defects showed a significant direct effect, but only cleft lip with/ without cleft palate had a significant risk for the indirect effect. Out of the total effect of a f-SEL risk on cleft lip $(\mathrm{OR}=1.43)$, an $\mathrm{OR}=1.42$ corresponded to a direct effect, while an $\mathrm{OR}=1.01$ corresponded to an indirect effect. Only cleft lip with/without cleft palate showed a significant OR in deprived regions, independent from the f-SEL. That is to say, out of the total effect of the f-SEL on cleft lip, 3.4\% may be due to the conditions ofthe place of maternal residence (Table 4). Likewise, both anomalies showed increased and significant ORs among mothers with a low f-SEL who live in regions with a high r-SEL (interaction effect: cleft lip $S=1.37$, ventricular septal defect $\mathrm{S}=6.21)($ Table 5).

\section{DISCUSSION}

Lack of family planning and poor antenatal care were the most relevant characteristics of mothers with a low f-SEL based on the outcome measures associated with this risk group: high number of pregnancies, few antenatal care visits, parental age ( $\leq 19$ years old or $\geq 35$ years old), higher frequency of urinary tract infections, and higher use of abortion medications. In Argentina, approximately 50\% of pregnancies are not planned, ${ }^{20}$ and this study confirms the risks of such reproductive behavior.

A higher risk for cleft lip with/without cleft palate and ventricular septal defects was observed

TABLE 3. Distribution of adverse social determinants by cases and controls. Propensity scores for adjusted social determinants

\begin{tabular}{|c|c|c|c|c|c|}
\hline \multirow[b]{2}{*}{ Outcome measures } & & \multicolumn{2}{|c|}{ Cases } & \multicolumn{2}{|c|}{ Controls } \\
\hline & & $\mathbf{N}$ & $\%$ & $\mathbf{N}$ & $\%$ \\
\hline \multirow{5}{*}{$\begin{array}{l}\text { Family SEL } \\
\text { index }\end{array}$} & Q1 - low SEL & 954 & 21 & 2410 & 18 \\
\hline & Q2 & 610 & 13 & 1917 & 14 \\
\hline & Q33 & 681 & 15 & 2002 & 15 \\
\hline & Q4 & 1072 & 24 & 3429 & 26 \\
\hline & Q5 - high SEL & 1228 & 27 & 3586 & 27 \\
\hline \multirow{3}{*}{$\begin{array}{l}\text { Demographic } \\
\text { characteristics }\end{array}$} & Paternal age $\leq 19$ years old & 332 & 7 & 953 & 7 \\
\hline & Paternal age $\geq 39$ years old & 754 & 16 & 1484 & 11 \\
\hline & Sibship & 26 & 0.5 & 50 & 0.4 \\
\hline Ethnic descent & Native & 4223 & 87 & 11519 & 87 \\
\hline \multirow{7}{*}{$\begin{array}{l}\text { Reproductive } \\
\text { behavior }\end{array}$} & Maternal age $\leq 19$ years old & 920 & 18 & 2703 & 20 \\
\hline & Maternal age $\geq 35$ years old & 963 & 19 & 1515 & 11 \\
\hline & Primigravidity & 1339 & 26 & 3794 & 28 \\
\hline & Multigravida $\geq 4$ & 1920 & 38 & 4375 & 33 \\
\hline & Impaired fecundity & 395 & 8 & 1268 & 10 \\
\hline & Period living together $<1$ year & 168 & 5 & 300 & 3 \\
\hline & Different father & 473 & 15 & 1141 & 13 \\
\hline Antenatal care & Antenatal care visits $\leq 5$ & 1521 & 42 & 3065 & 33 \\
\hline \multirow{3}{*}{$\begin{array}{l}\text { Exposure during } \\
\text { the first trimester }\end{array}$} & Acute conditions & 1711 & 35 & 3717 & 28 \\
\hline & Chronic conditions & 840 & 17 & 1693 & 13 \\
\hline & Use of medications & 2587 & 53 & 6116 & 46 \\
\hline \multirow{3}{*}{$\begin{array}{l}\text { Regional development } \\
\text { level (r-SEL) }\end{array}$} & Low & 1745 & 34 & 4363 & 33 \\
\hline & Middle & 2353 & 46 & 6643 & 50 \\
\hline & High & 989 & 19 & 2338 & 17 \\
\hline \multirow{4}{*}{$\begin{array}{l}\text { Propensity } \\
\text { scores } \\
(\mathrm{X} \pm \mathrm{SD})\end{array}$} & Maternal age & $25.7 \pm 4.5$ & & $25.6 \pm 5.4$ & \\
\hline & Gravidity order & $3.1 \pm 2.0$ & & $3.0 \pm 1.9$ & \\
\hline & Antenatal care visits & $5.8 \pm 2.5$ & & $5.9 \pm 2.4$ & \\
\hline & Native descent & $89.4 \%$ & & $88.9 \%$ & \\
\hline
\end{tabular}


among mothers with a low f-SEL who live in high r-SEL regions, regardless maternal age, number of pregnancies, number of antenatal care visits, and native descent. This last observation is greatly relevant given that ventricular septal defect has been related to a higher risk of native descent, ${ }^{21}$ gravidity order, ${ }^{22}$ and few antenatal care visits. ${ }^{23}$ Similarly, the effect of maternal age has been reported in connection with this defect. ${ }^{24}$

After adjusting for the propensity score, cases and controls presented, in average, the same maternal age, gravidity order, number of

TABLE 4.Risk for 14 congenital anomalies by f-SEL and $r$-SEL

\begin{tabular}{|c|c|c|c|c|c|c|c|c|c|c|}
\hline & \multicolumn{6}{|c|}{ Family socioeconomic level } & & \multicolumn{3}{|c|}{ SEL effect } \\
\hline & Q1 & Q2 & Q3 & Q4 & Q5 & Tendency & & Direct & Indirect & \\
\hline Anomaly & OR & OR & OR & OR & OR & OR & $\mathrm{p}$ & OR & OR & $\%$ \\
\hline Gastroschisis & 0.86 & 0.79 & 0.97 & 1.00 & 1.00 & 0.93 & 0.390 & 0.84 & 0.99 & 5.4 \\
\hline Anencephaly & 1.20 & 1.42 & 1.40 & 1.11 & 1.00 & 1.05 & 0.346 & 1.20 & 1.00 & 0.1 \\
\hline Spina bifida & 0.79 & 0.94 & 0.84 & 0.87 & 1.00 & 0.96 & 0.517 & 0.79 & 0.99 & 3.9 \\
\hline Hydrocephalus & 1.36 & 0.81 & 0.73 & 0.79 & 1.00 & 1.06 & 0.271 & 1.37 & 0.98 & 0.0 \\
\hline Microtia & 1.09 & 0.71 & 0.89 & 1.18 & 1.00 & 0.97 & 0.736 & 1.09 & 1.00 & 5.7 \\
\hline Cleft lip & $1.43^{*}$ & 1.16 & 1.36 & 1.09 & 1.00 & 1.08 & 0.067 & $1.42^{*}$ & $1.03^{*}$ & 3.4 \\
\hline Cleft palate & 0.44 & 0.78 & 1.85 & 1.14 & 1.00 & 0.89 & 0.256 & 0.42 & 1.01 & 0.0 \\
\hline Imperforate anus & 0.64 & 0.84 & 0.80 & 0.93 & 1.00 & 0.92 & 0.357 & 0.63 & 1.01 & 0.0 \\
\hline Truncus arteriosus & 0.85 & 2.08 & 1.45 & 1.38 & 1.00 & 1.05 & 0.512 & 0.86 & 0.99 & 8.1 \\
\hline Ventricular septal defect & $1.39^{*}$ & 1.19 & 1.42 & 0.95 & 1.00 & 1.11 & 0.045 & $1.38^{*}$ & 1.01 & 2.3 \\
\hline Hypospadias & 0.96 & 0.86 & 0.58 & 0.97 & 1.00 & 1.00 & 0.983 & 0.96 & 0.99 & 12.1 \\
\hline Postaxial polydactyly & 1.08 & 0.63 & 0.95 & 0.80 & 1.00 & 1.00 & 0.851 & 1.08 & 1.00 & 0.1 \\
\hline Preaxialpolydactyly & 1.65 & 1.67 & 0.89 & 1.11 & 1.00 & 1.14 & 0.095 & 1.66 & 0.99 & 0.0 \\
\hline Hydronephrosis & 0.45 & 0.43 & 0.40 & 0.52 & 1.00 & 0.79 & 0.021 & 0.46 & 0.98 & 2.4 \\
\hline
\end{tabular}

Low f-SEL: Q1; high f-SEL: Q5 (reference group).

${ }^{*} \mathrm{p}<0.01$.

TABLE 5. Risk for 14 congenital anomalies by interaction between a low $f$-SEL + a high $r$-SEL and each individually

\begin{tabular}{lccccccc}
\hline Effects & \multicolumn{2}{c}{ Low f-SEL + high r-SEL } & \multicolumn{2}{c}{ High r-SEL } & \multicolumn{3}{c}{ Low f-SEL } \\
\hline Anomaly & OR & $\mathbf{9 5} \%$ CI & OR & $\mathbf{9 5} \%$ CI & OR & 95\% CI & S \\
\hline Gastroschisis & 1.10 & $0.42-2.83$ & 0.64 & $0.34-1.19$ & 0.53 & $0.21-1.34$ & -0.120 \\
Anencephaly & 1.27 & $0.73-2.24$ & 0.93 & $0.65-1.34$ & 0.77 & $0.46-1.28$ & -0.900 \\
Spina bifida & 0.72 & $0.36-1.45$ & 0.76 & $0.52-1.10$ & 0.83 & $0.52-1.35$ & 0.683 \\
Hydrocephalus & 1.58 & $0.92-2.70$ & 0.50 & $0.32-0.79$ & 1.18 & $0.75-1.83$ & -1.813 \\
Microtia & 1.06 & $0.41-2.74$ & 1.21 & $0.73-1.99$ & 1.25 & $0.65-2.40$ & 0.130 \\
Cleft lip & 1.74 & $1.14-2.64$ & 1.32 & $1.01-1.73$ & 1.22 & $0.85-1.76$ & 1.370 \\
Cleft palate & 0.31 & $0.42-2.32$ & 1.69 & $0.96-2.96$ & 0.62 & $0.21-34.99$ & -2.226 \\
Imperforate anus & 0.84 & $0.25-2.78$ & 1.27 & $0.73-2.20$ & 0.81 & $0.33-1.94$ & -2.000 \\
Truncus arteriosus & 0.55 & $0.19-1.53$ & 0.73 & $0.44-1.20$ & 0.62 & $0.30-1.27$ & 0.692 \\
VSD & 1.87 & $1.14-3.05$ & 1.06 & $0.76-1.49$ & 1.08 & $0.69-1.70$ & 6.214 \\
Hypospadias & 1.29 & $0.54-3.05$ & 0.74 & $0.44-1.26$ & 1.04 & $0.54-2.00$ & -1.318 \\
Postaxial polydactyly & 1.02 & $0.59-1.77$ & 1.07 & $0.79-1.44$ & 1.37 & $0.95-1.97$ & 0.045 \\
Preaxialpolydactyly & 1.26 & $0.55-2.88$ & 0.97 & $0.57-1.66$ & 1.39 & $0.76-2.55$ & 0.722 \\
Hydronephrosis & 0.30 & $0.04-2.20$ & 0.57 & $0.28-1.13$ & 0.78 & $0.33-1.86$ & 1.077 \\
\hline
\end{tabular}

r-SEL: high UBNs (UBNs $>19 \%$ ).

Low r-SEL: Q1.

VSD: ventricular septal defect. 
antenatal care visits and rate of native descent; therefore, these outcome measures would not interfere with the interpretation of results. However, a residual effect cannot be ruled out.

There have been reports in the literature indicating an association between a low f-SEL and cleft lip with/without cleft palate ${ }^{25,10}$ with a moderate risk 1.5-1.7 times higher, and within the range observed in this study.

When the outcome measures that make up the f-SEL are analyzed independently, only paternal education level showed an increased risk. The paternal employment modality was reported in the literature as a risk factor for cleft lip ${ }^{26}$ given that they are often farmers and painters who are exposed to agrochemicals and solvents, which may result in an indirect exposure for mothers. Other likely explanation may be maternal lifestyle which entails a higher degree of exposure to alcohol and tobacco ${ }^{27,28}$ or environmental contaminants ${ }^{29}$ during pregnancy because they live in regions subjected to poor regulation regarding toxic agent management and safety.

Heart diseases are characterized by a low heritability, an environmental etiology and for occurring at an early stage during embryogenesis. A higher risk was reported for different types of congenital heart diseases ${ }^{30}$ among lower social strata. ${ }^{31,32}$ Mothers of newborn infants with a ventricular septal defect have a lower socioeconomic level and a higher percentage of tobacco and alcohol use. ${ }^{33}$

When analyzed independently, none of the outcome measures that make up the f-SEL index showed an increased risk for ventricular septal defect.

Most congenital anomalies have a multifactoral etiology, and the greatest vulnerability to environmental agents takes place over the first days or months of gestation while women generally are not aware they are pregnant. This implies that the risk observed in lower socioeconomic levels may be the direct result of lack of parental information during antenatal care or an indirect effect of the region of residence (lack of access to hospitals with adequate technology to detect and diagnose diseases, regions of greater violence, pollution, etc.) or the maternal lifestyle (higher degree of exposure to alcohol, tobacco, other drugs, etc.), which have not been assessed in this study but are obviously closely related to the poverty index.

\section{Strengths}

The relevance and innovation of this study lie on the number of assessed congenital anomalies, the large sample size, the evaluation of the SEL effect using two hierarchy levels, and the implementation of a comprehensive methodological approach.

The study was conducted as per the operational rules of the ECLAMC, a South American hospital database. In addition to collecting information on more than 50 risk factors, the diagnostic definition of congenital anomalies was performed by trained professionals.

The methodology employed was the most appropriate so as to respect the hierarchal structure of data at the analysis level (familiar and regional) and to control confounding factors using the propensity score technique, therefore ensuring that the distribution of confounding outcome measures was equal between cases and controls.

The reason for selecting the study period was that, in Argentina, the 1990s were characterized by financial and social instability leading to the 2001 economic crisis, an adequate period for this type of study.

\section{Weaknesses}

It is not possible to rule out possible information and confounding biases, which are inherent to case-controls studies. The definition of social heterogeneity regions implies an ecological fallacy bias, which means inferring individual risks from grouped data. That is to say, middle class families living in poor regions are classified as poor families.

In spite of this, a wrong classification would make no difference (for cases and controls). Other possible information bias is the use of the hospital where the birth occurred as an approximate indicator of the place of residence; however, deviation in risk estimations may occur when including severe cases referred to hospitals to higher complexity. Certain confounding factors were not measured, such as smoking, alcohol consumption or other factors related to the lifestyle during pregnancy, so they could have a residual effect on risk estimations.

\section{CONCLUSION}

Out of 14 analyzed congenital anomalies, cleft lip with/without cleft palate and ventricular septal defect were significantly associated with the two poverty levels analyzed after adjusting 
the values for maternal age, gravidity order, number of antenatal visits and native descent. There was a higher risk for both anomalies among low socioeconomic level families who live in high r-SEL regions.

It has been observed that mothers with a low socioeconomic level and who live in less developed regions (high r-SEL) are exposed to risk factors related to pregnancy planning, a higher frequency of chronic and infectious diseases during pregnancy, which are probably not treated, and exposure to teratogenic agents.

Additional studies are necessary to analyze the risk factors herein described according to a causative hypothesis so as to better and more specifically understand the effects of adverse social determinants on congenital anomalies.

\section{REFERENCES}

1. Little J, Elwood H. Socio-economic status and occupation. En: Elwood JM, Little J, Elwood H, eds. Epidemiology and control of neural tube defects. Oxford: Oxford University Press; 1992.

2. Bartley M, Blane D. Socioeconomic deprivation in Britain. Appropriateness of deprivation indices must be ensured. BMJ 1994;309(6967):1479.

3. Singh GK, Kogan MD. Widening socioeconomic disparities in us childhood mortality, 1969-2000. Am J Public Health 2007;97:1658-65.

4. Buka S, Brennan R, Rich-Edwards J, Raudenbush S, et al. Neighborhood support and the birth weight of urban infants. Am J Epidemiol 2003;157:1-8.

5. O'Campo P, Burke J, Culhane J, Elo I, et al. Neighborhood Deprivation and Preterm Birth among Non-Hispanic Black and White Women in Eight Geographic Areas in the United State. Am J Epidemiol 2008;167:155-63.

6. Clark J, Mossey P, Sharp L, Little J. Socioeconomic status and orofacial clefts in Scotland, 1989 to 1998. Cleft PalateCraniofac J 2003;40:481-5.

7. Grewal J, Carmichael SL, Song J, Shaw GM. Neural tube defects: an analysis of neighbourhood-and individual-level socio-economic characteristics. Paediatr Perinat Epidemiol 2009;23:116-24.

8. Vrijheid M, Dolk H, Stone D, Abramsky L, et al. Socioeconomic inequalities in risk of congenital anomaly. Arch Dis Child 2000;82:349-52.

9. CarmichaelSL, Ma C, Shaw GM. Socioeconomic measures, orofacial clefts, and conotruncal heart defects in California. Birth Defects Res A Clin Mol Teratol 2009;85:850-7.

10. Departamento de Salud Reproductiva e Investigación de la Organización Mundial de la Salud (OMS/RHR) y Johns Hopkins Bloomberg School of Public Health/ Center for Communication Programs (CCP), Project INFO. Planificación familiar: Un manual mundial para proveedores. Baltimore y Ginebra: CCP y OMS; 2007.

11. Wehby GL, Murray JC, Castilla EE, López-Camelo JS, et al. Prenatal care demand and its effects on birth outcomes by birth defect status in Argentina. Econ Hum Biol 2009;7:84-95.

12. Wehby GL, Prater K, McCarthy AM, Castilla EE, et al. The impact of maternal smoking during pregnancy on early child neurodevelopment. J Hum Cap 2011;5:207-54.
13. Castilla EE, Orioli IM. ECLAMC: The Latin-American collaborative study of congenital malformations. Community Genetics 2004;7:76-94.

14. Kulldorff M, Nagarwalla N. Spatial disease clusters: Detection and inference. Stat Med 1994;14:799-810.

15. Imbens GW. The role of the propensity score in estimating dose-response functions. Biometrika 2000;87(3):706-10.

16. Woolf B. On estimating the relation between blood group disease. Ann Hum Genet 1995;19:251-3.

17. Khan H, Shaw E. Multilevel logistic regression analysis applied to binary contraceptive prevalence data. J Data Sc 2011;9(1):93-110.

18. Erikson R, Goldthorpe JH, Jackson M, Yaish M, Cox DR. On class differentials in educational attainment. Proceed Nat Acad Sc 2005;102:9730-3.

19. Rothman KJ. Synergy and antagonism in cause-effect relationships. Am J Epidemiol 1974;99:385-8.

20. Gadow EC, Paz JE, López-Camelo JS, Dutra MG, et al. Unintended pregnancies in women delivering at 18 South American hospitals. NFP-ECLAMC Group. Latin American Collaborative Study of Congenital Malformations. Human Reprod 1998;13(7):1991-5.

21. Mossey PA, Little J. Epidemiology of oral clefts: an international perspective. En: Wyszynski D, ed. Cleft Lip \& Palate. New York: Oxford University Press; 2002. Pags.127-58.

22. Gili JA, Poletta FA, Campaña H, Comas B, et al. Is gravidity $4+$ a risk factor for oral clefts? A case-control study in eight South American countries using structural equation modeling. Cleft Palate-Craniofacial J 2013;50(5):591-6.

23. Nyarko KA, López-Camelo J, Castilla EE, Wehby GL. Does the relationship between prenatal care and birth weight vary by oral clefts? Evidence using South American and United States samples. J Pediatr 2013;162(1):42-9.

24. ReefhuisJ,Honein MA. Maternal age and non-chromosomal birth defects, Atlanta - 1968-2000: Teenager or thirtysomething, who is at risk? Birth Defects Res A Clin Mol Teratol 2004;70:572-9.

25. Yang J, Carmichael S, Canfield M, Song J, et al. Socioeconomic status in relation to selected birth defects in a large multicentered US case - control study. Am J Epidemiol 2008;167:145-54.

26. Qi L, Liu J, Zhang Y, Wang J, et al. Risk factors for nonsyndromic oral clefts: a matched case-control study in Hubei Province, China. Oral Dis 2013. En prensa.

27. Munger RG, Romitti PA, Daack-Hirsch S, Burns TL, et al. Maternal alcohol use and risk of orofacial cleft birth defects. Teratology 1996;54(1):27-33.

28. Lieff S, Olshan AF, Werler M, Strauss RP, et al. Maternal cigarette smoking during pregnancy and risk of oral clefts in newborns. Am J Epidemiol 1999;150:683-94.

29. Croen LA, Shaw GM, Sanbonmatsu L, Selvin S, Buffler PA. Maternal residential proximity to hazardous waste sites and risk for selected congenital malformations. Epidemiology 1997;8(4):347-54.

30. Kučienè R, Dulskienè V. Maternal socioeconomic and lifestyle factors during pregnancy and the risk of congenital heart defects. Medicina (Kaunas) 2009;45:904-9.

31. Olshan F, Baird PA, Lo KH. Socioeconomic status and the risk of birth defects. Am J Epidemiol 1991;134:778-9.

32. Correa-Villaseñor A, McCarter R, Downing J, Ferencz C. White-black differences in cardiovascular malformations in infancy and socioeconomic factors. The Baltimore-Washington Infant Study Group. Am J Epidemiol 1991;134:393402.

33. Vereczkey A,Kósa Z,Csáky-Szunyogh M,Urbán R, Czeizel AE. Ventricular septal defects in function of maternal sociodemographic aspects. Cent Eur J Med 2012;7(4):511-22. 


\section{Annex I}

\section{Thirty-nine hospitals from Argentina participating in the Latin-American Collaborative Study of Congenital Malformations and level of unmet basic needs, 1992-2001 period}

\begin{tabular}{|c|c|c|c|}
\hline Name of the Hospital & District/municipality/school district & Province & $\%$ of UBN \\
\hline Suizo-Argentino & District I & CABA (Autonomous City of Buenos Aires) & 7.1 \\
\hline Fernández & District I & CABA (Autonomous City of Buenos Aires) & 7.1 \\
\hline Sardá & District VI & CABA (Autonomous City of Buenos Aires) & 11.4 \\
\hline Italiano & District VI & CABA (Autonomous City of Buenos Aires) & 11.4 \\
\hline Santojanni & District XX & CABA (Autonomous City of Buenos Aires) & 7.9 \\
\hline Materno Infantil "Ana Goitia" & Avellaneda & Bs. As. & 10.7 \\
\hline Lucio Meléndez & Almirante Brown & Bs. As. & 19.3 \\
\hline Ricardo Finochietto & Almirante Brown & Bs. As. & 19.3 \\
\hline Sofía de Santamarina & Esteban Echeverría & Bs. As. & 20.4 \\
\hline Privado de Comunidad & General Pueyrredón & Bs. As. & 10.9 \\
\hline Interzonal Materno Infantil & General Pueyrredón & Bs. As. & 10.9 \\
\hline Del Niño y de la Madre & General Pueyrredón & Bs. As. & 10.9 \\
\hline Eva Perón & General San Martín & Bs. As. & 13.0 \\
\hline Italiano & La Plata & Bs. As. & 12.8 \\
\hline Narciso López & Lanús & Bs. As. & 11.7 \\
\hline Luisa de Gandulfo & Lomas de Zamora & Bs. As. & 17.2 \\
\hline Materno Provincial & Capital City & Córdoba & 12.2 \\
\hline Ntra. Sra. de la Misericordia & Capital City & Córdoba & 12.2 \\
\hline Tránsito Cáceres de Allende & Capital City & Córdoba & 12.2 \\
\hline Concepción & Capital City & Córdoba & 12.2 \\
\hline Materno Neonatal & Capital City & Córdoba & 12.2 \\
\hline Andrés Ísola & Viedma & Chubut & 13.8 \\
\hline Zonal de Esquel & Futaleufú & Chubut & 21.6 \\
\hline Centenario & Gualeguaychú & Entre Ríos & 12.7 \\
\hline Mat. Inf. San Roque & Paraná & Entre Ríos & 11.3 \\
\hline Pablo Soria & Dr. Manuel Belgrano & Jujuy & 20.9 \\
\hline San Roque & Dr. Manuel Belgrano & Jujuy & 20.9 \\
\hline Regional Dr. Vera Barros & Capital City & La Rioja & 17.6 \\
\hline Fleming & Capital City & Mendoza & 8.3 \\
\hline Italiano & Guaymallén & Mendoza & 13.5 \\
\hline Regional Alfredo Perrupato & San Martín & Mendoza & 16.2 \\
\hline Madariaga & Capital City & Misiones & 20.8 \\
\hline Área El Bolsón & Bariloche & Río Negro & 20.3 \\
\hline Complejo Sanitario San Luis & Capital City & San Luis & 13.2 \\
\hline Rivadavia & Capital City & San Luis & 13.2 \\
\hline Martin & Rosario & Santa Fe & 14.7 \\
\hline Roque Sáenz Peña & Rosario & Santa Fe & 14.7 \\
\hline Ntra. Sra. de las Mercedes & Capital City & Tucumán & 17.5 \\
\hline Regional de Ushuaia & Ushuaia & T. del Fuego & 17.6 \\
\hline
\end{tabular}

UBNs: unmet basic needs. 